\title{
Avaliação das propriedades tecnológicas de cerâmica vermelha incorporada com resíduo de rocha ornamental proveniente do tear de fio diamantado
}

\section{(Evaluation of technological properties of red ceramics incorporated with dimension stone waste from diamond wire loom)}

\author{
S. P. Taguchi, J. C. Santos, T. M. Gomes, N. A. Cunha \\ Universidade Federal do Espirito Santo - UFES, Campus de Alegre, Alto Universitário s/n, C.P. 16, Alegre, \\ ES 29500-000 \\ simoneptb@hotmail.com.br,julmarcs@gmail.com,tiagomarvilaufes@gmail.com,natali_altoe@hotmail.com
}

\begin{abstract}
Resumo
O aumento expressivo na produção e consumo de rochas ornamentais tem causado impactos ambientais indesejáveis. No processo de serragem dos blocos são gerados resíduos na forma de lama, que quando seca torna-se um resíduo sólido não biodegradável. Estes resíduos apresentam alguns constituintes em sua composição similares aos normalmente apresentados na massa argilosa utilizada na fabricação de produtos de cerâmica vermelha. O presente trabalho pretende avaliar as propriedades tecnológicas da cerâmica vermelha incorporada com resíduo de rochas ornamentais proveniente do tear de fio diamantado. Foram preparadas cinco composições argilosas contendo 0, 20,40,60 e 80\% de resíduo de rocha ornamental. Os corpos de prova foram conformados por prensagem uniaxial com dimensões aproximadamente de $110 \mathrm{x} 25 \mathrm{x} 10 \mathrm{~mm}^{3}$. Foram investigadas as seguintes condições de sinterização: $900{ }^{\circ} \mathrm{C} / 1 \mathrm{~h} \mathrm{e} 2 \mathrm{~h}, 1000{ }^{\circ} \mathrm{C} / 1 \mathrm{~h}$ e $2 \mathrm{~h} \mathrm{e} 1100{ }^{\circ} \mathrm{C} / 1 \mathrm{~h} \mathrm{e} 2 \mathrm{~h}$. As amostras de cerâmica vermelha sinterizadas foram submetidas a ensaios de absorção de água, densidade aparente e tensão de ruptura à flexão. A estatística de Weibull foi usada para analisar a reprodutibilidade e confiabilidade do ensaio de resistência mecânica. Os resultados mostraram que a condição de sinterização mais favorável foi de $1100^{\circ} \mathrm{C} / 1$ h e a fração de $60 \%(\mathrm{~m} / \mathrm{m})$ de resíduo de rocha ornamental na argila pura é a maior sem prejudicar a qualidade técnica do produto final. Ainda, a destinação do resíduo de rocha ornamental para fabricação de cerâmica vermelha minimiza o impacto ambiental que o mesmo provoca no meio ambiente.
\end{abstract}

Palavras-chave: aproveitamento de resíduo, rochas ornamentais, cerâmica vermelha, propriedades mecânicas.

\begin{abstract}
The increase in the production and use of dimension stones promotes undesirable environmental impacts. In the sawing process of blocks, the slurry is generated and becomes a non biodegradable solid waste after drying. These wastes have some composition similar to that of some components present in the clay mass used in the manufacture of red ceramic. This study aims to evaluate the technological properties of red ceramic incorporated with dimension stone waste from the diamond wire loom. The compositions were prepared with 0,20,40,60 and $80 \mathrm{wt} . \%$ dimension stone waste in the clay. The samples were uniaxially pressed with dimensions approximately $110 \times 25 \times 10 \mathrm{~mm}^{3}$. The following sintering conditions were investigated: $900{ }^{\circ} \mathrm{C}, 1000{ }^{\circ} \mathrm{C}$ and $1100{ }^{\circ} \mathrm{C}$, all for 1 and $2 \mathrm{~h}$. The sintered samples were characterized by water absorption, density and flexural strength. The Weibull statistics was used to analyze the reproducibility and reliability of the mechanical strength testing. The results showed that the most favorable condition for sintering was $1100{ }^{\circ} \mathrm{C} / 1$ h and that the use of up to $60 \mathrm{wt} . \%$ dimension stone waste in pure clay is viable for production of red ceramics. Moreover, the allocation of the dimension stone waste for the manufacture of red ceramics minimizes the environmental impact on the environment.
\end{abstract}

Keywords: dimension stones, red ceramic, mechanical properties.

\section{INTRODUÇÃO}

A indústria de rochas ornamentais experimentou um notável crescimento nos últimos anos, impulsionado pelo setor de construção civil. O segmento de rochas ornamentais somou exportações de US\$ 421,15 milhões no período de janeiro a maio de 2012. Registrou-se neste período uma variação positiva de $12,29 \%$ no faturamento e 7,34\% no volume físico das exportações do país frente ao mesmo período do ano de 2011. As perspectivas de 
Tabela I - Composições das misturas de resíduo de rochas ornamentais e argila.

[Table I - Compositions of dimension stone waste and clay mixture.]

\begin{tabular}{ccc}
\hline Amostra & $\begin{array}{c}\text { Resíduo } \\
(\%)\end{array}$ & $\begin{array}{c}\text { Argila } \\
(\%)\end{array}$ \\
\hline AR0 & 0 & 100 \\
AR20 & 20 & 80 \\
AR40 & 40 & 60 \\
AR60 & 60 & 40 \\
AR80 & 80 & 20 \\
\hline
\end{tabular}

contínuos crescimentos neste setor são notáveis [1]. O município de Cachoeiro do Itapemirim no estado do Espírito Santo é o grande polarizador neste cenário, pois, além de suprir o mercado nacional, grande parte da produção de rochas ornamentais destina-se para exportação. Dada sua importância para a economia, este setor causa preocupação, pois o aumento da produção contribui paulatinamente para o aumento dos resíduos que, geralmente, são depositados em lagos e aterros [2]. A reutilização destes resíduos consiste na forma mais eficiente para minimizar seu descarte no meio ambiente. Os resíduos de rochas ornamentais apresentam uma composição favorável para a incorporação nas massas de cerâmica vermelha por serem constituídos majoritariamente por óxido de silício $\left(\mathrm{SiO}_{2}\right)$, óxido de alumínio $\left(\mathrm{Al}_{2} \mathrm{O}_{3}\right)$, óxido de cálcio $(\mathrm{CaO})$, óxido de ferro $\left(\mathrm{Fe}_{2} \mathrm{O}_{3}\right)$ e óxidos alcalinos $\left(\mathrm{K}_{2} \mathrm{O}, \mathrm{Na}_{2} \mathrm{O}\right)$. A massa padrão tende a enriquecer-se de compostos fundentes, que são importantes na sinterização das peças e formulação dos produtos [2].

O estudo das matérias primas empregadas nas indústrias de cerâmica vermelha, busca informações que possibilite o melhoramento do processo produtivo e desenvolvimento de produtos. A investigação de todos os aspectos baseia-se nas análises que se reflete na obtenção de telhas e tijolos de melhor qualidade, seja por mudanças nas formulações das misturas, seja por melhorias no processo de fabricação [3].

A plasticidade, propriedade de certos sólidos serem moldados sem apreciável variação de volume ou ruptura, de misturas de argila com resíduo de rochas ornamentais é reduzida quando se aumenta a fração de resíduo na massa cerâmica [4].

Foi observado um aumento no valor de absorção de água proporcional a adição de resíduos de rochas ornamentais de $0,10,20$ e $30 \%(\mathrm{~m} / \mathrm{m})$ [5]. Para a adição de $20 \%$ de resíduo de rocha ornamental o valor de absorção de água aumentou de $11,5 \%$ para $14 \%$. A retração linear para $0 \%$ e $30 \%(\mathrm{~m} / \mathrm{m})$ de resíduo foi $8,1 \%$ e $5,7 \%$, respectivamente. Os valores de tensão de ruptura à flexão obtidos para a composição de $20 \%$ e $0 \%$ em massa foram próximos, sendo que existe uma tendência à diminuição da resistência mecânica conforme aumenta a quantidade de resíduo [6]. As amostras sinterizadas a $1050{ }^{\circ} \mathrm{C}$ apresentaram $11 \mathrm{MPa}$ e $14 \mathrm{M}$ Pa de resistência à flexão para $20 \%$ e $0 \%$ de resíduo, respectivamente. A possibilidade de utilizar os resíduos de rochas ornamentais como matéria-prima cerâmica alternativa na produção de blocos e revestimentos cerâmicos, incorporando de 20 a $60 \%$ de resíduo foi caracterizada e avaliada [7]. Esses resultados mostraram que os resíduos apresentam características físicas e mineralógicas semelhantes as das matérias-primas cerâmicas convencionais e que corpos cerâmicos formulados com resíduos apresentam características dentro das especificações da normalização brasileira para blocos $[8,9]$.

Existe uma diversidade de resultados referente às propriedades das cerâmicas vermelhas obtidas com a adição de resíduos de rochas ornamentais. Tal fato se deve a heterogeneidade dos tipos de resíduos e variações de composições estudadas, além das particularidades de processamento cerâmico aplicada em cada trabalho. Geralmente é enfocado o uso de resíduo de rocha ornamental proveniente de teares que utilizam lâminas metálicas e granalha $[2,5,6]$. Neste trabalho foi utilizado um resíduo de rocha ornamental proveniente do tear de fio diamantado, que possui insignificante quantidade de óxido de ferro, e, portanto, com potencial de aplicações mais nobres. Altas concentrações de óxido de ferro sugerem que a coloração da cerâmica será avermelhada após a sinterização. Para telhas de coloração natural, por exemplo, isto não inviabilizaria sua aplicação como produto cerâmico. Entretanto, para produtos esmaltados, quanto mais escura a base, maior a quantidade de opacificantes e corantes no engobe e esmaltes utilizados [10].

O objetivo deste trabalho é estudar as propriedades tecnológicas de cerâmica vermelha incorporada com diferentes proporções de resíduo de rocha ornamental oriundo de tear de fio diamantado, para avaliar sua viabilidade como produto aplicado à construção civil.

\section{MATERIAIS E MÉTODOS}

Os materiais utilizados foram argila coletada na cerâmica Abud Wagner em Campos de Goytacazes, RJ, e o resíduo de rocha ornamental oriundo do tear de fio diamantado de uma empresa de Cachoeiro de Itapemirim. A argila foi seca em estufa a $110{ }^{\circ} \mathrm{C}$ por $24 \mathrm{~h}$, moída em um moinho de bolas por $4 \mathrm{~h}$ e passada em peneira 32 mesh. O resíduo de rocha ornamental foi seco em estufa a $120^{\circ} \mathrm{C}$ e passado na peneira de 32 mesh para homogeneizar o tamanho das partículas.

A análise química da argila e do resíduo foi determinada por análise semi-quantitativa sem padrões com análise de elementos químicos de flúor a urânio, em espectrômetro por fluorescência de raios X Axios Advanced PANalytical. A perda ao fogo (PF) foi efetuada a $1050{ }^{\circ} \mathrm{C}$ por $1 \mathrm{~h}$. Já as fases cristalinas foram analisadas em um difratômetro de raios $\mathrm{X}$ com radiação Cuk $\alpha(\lambda=1,5418 \AA$ ) no intervalo angular $2 \theta=$ $4-90^{\circ}$, passo angular $0,02^{\circ}$ e tempo de contagem $2 \mathrm{~s}$, a fim de identificar as fases cristalinas por meio dos arquivos JCPDS.

Foram preparadas posteriormente cinco massas cerâmicas contendo adições de até $80 \%$ em peso de resíduo de rocha ornamental (Tabela I). Os corpos de prova foram conformados por prensagem uniaxial nas dimensões de aproximadamente 110 x $25 \times 10 \mathrm{~mm}^{3}$, secos 
a $110{ }^{\circ} \mathrm{C}$ em estufa por $48 \mathrm{~h}$. No primeiro momento buscou-se investigar as melhores condições de sinterização em relação à temperatura e tempo. Para isso, sinterizou-se a amostra AR0 em 900,1000 e $1100{ }^{\circ} \mathrm{C}$ por $1 \mathrm{~h}$ e $2 \mathrm{~h}$. Foram analisadas a densidade aparente, absorção de água, retração linear e módulo de ruptura à flexão das amostras para determinar a melhor condição de sinterização. Analisou-se também o módulo de Weibull a fim de estudar a reprodutibilidade das cerâmicas vermelhas produzidas.

Para o ensaio de absorção de água foram usadas as normas ABNT NBR 15270-3 [11] e 8947 [12]. Para tal, as amostras foram secas em estufa a $110^{\circ} \mathrm{C}$ até atingirem massa constante e pesadas em balança analítica. Mergulharam-se os corpos de prova em água fervente. Após $2 \mathrm{~h}$ retirou-se a fonte de calor do recipiente e colocou-se os corpos de prova sob circulação de água à temperatura ambiente para ser atingido o equilíbrio da temperatura. Pesou-se os corpos de prova. A absorção de água ( $A b s)$ é dada pela equação $\mathrm{A}$, sendo $m_{0}$ a massa seca e $m$ a massa saturada:

$$
\text { Abs }=\frac{\left(m-m_{o}\right)}{m_{o}}
$$

O comprimento das amostras foi medido antes e após a sinterização para o cálculo de retração linear (RL).

O módulo de ruptura à flexão em carregamento de três pontos das amostras foi determinado em uma máquina universal de ensaios mecânicos. As amostras foram previamente submetidas a um processo de acabamento com o objetivo de minimizar os defeitos que podem influenciar o ensaio de flexão. Os valores do módulo de ruptura de flexão $(M R F)$ foram obtidos utilizando a equação B:

$$
\mathrm{MRF}=3 \mathrm{FL} /\left(2 \mathrm{~b} \mathrm{e}^{2}{ }_{\text {min }}\right)
$$

na qual F é a força em Newton, L é a distância entre as barras de apoio $(\mathrm{mm})$, b é a largura da amostra ao longo da ruptura após ensaio $(\mathrm{mm})$ e $\mathrm{e}_{\min }$ é a mínima espessura da amostra, medida na seção de ruptura, excluídas as bordas da seção $(\mathrm{mm})$.

O módulo de Weibull (w) foi obtido por meio da equação $\mathrm{C}$, sendo este o coeficiente angular da curva de $\ln \ln \left(1-\mathrm{P}_{\mathrm{f}}\right)^{-1}$ em função de $\ln \sigma$.

$$
\ln \ln \left(1-\mathrm{P}_{\mathrm{f}}\right)^{-1}=\ln \mathrm{V}-\mathrm{w} \ln \sigma_{0}+\mathrm{w} \ln \sigma
$$

sendo $\mathrm{P}_{\mathrm{f}}$ a probabilidade de fratura, $\mathrm{V}$ é o volume e $\sigma_{0}$ é um parâmetro de ajuste da equação, característico do material.
A probabilidade de fratura $\left(P_{f}\right)$ é estimada através da Equação D e, por conseguinte, seus resultados foram aplicados na Equação (C) para determinação do módulo de Weibull.

$$
\mathrm{P}_{\mathrm{f}}=(\mathrm{i}-0,5) / \mathrm{n}
$$

na qual i é o número correlativo a cada valor de tensão ordenada do menor ao maior, sem valores repetidos e n é o número total de valores de módulo de ruptura.

Foi determinada a melhor condição de sinterização da amostra AR0 para sinterizar as demais amostras, AR20, AR40, AR60 e AR80 e então caracterizada quanto à absorção de água, módulo de ruptura à flexão e retração linear, conforme descritos anteriormente.

\section{RESULTADOS E DISCUSSÃO}

A Tabela II mostra a composição química da argila e do resíduo de rochas ornamentais. Pode-se observar que a argila possui predominância de sílica $\left(\mathrm{SiO}_{2}\right)$, óxido de alumínio $\left(\mathrm{Al}_{3} \mathrm{O}_{3}\right)$ e óxido de ferro $\left(\mathrm{Fe}_{2} \mathrm{O}_{3}\right)$. Os compostos $\mathrm{SiO}_{2}$ e $\mathrm{Al}_{3} \mathrm{O}_{3}$ indicam a presença do argilomineral do grupo caulinita. $\mathrm{O}$ teor, não muito expressivo de $\mathrm{K}_{2} \mathrm{O}$ indica a presença do argilomineral da ilita e feldspato. A massa apresenta também percentual expressivo de hematita $\left(\mathrm{Fe}_{2} \mathrm{O}_{3}\right)$ e $\mathrm{TiO}_{2}$ responsáveis pela cor avermelhada após a sinterização. A argila apresenta $12,6 \%$ de perda ao fogo, indicando que na massa contém teor de material orgânico e/ou carbonatos.

A análise das fases cristalinas (DRX) da argila e do resíduo de rochas ornamentais está apresentada na Fig. 1. Nota-se uma predominância de quartzo $\left(\mathrm{SiO}_{2}\right)$ e caulinita $\left(\mathrm{Al}_{2} \mathrm{O}_{3} \cdot 2 \mathrm{SiO}_{2} \cdot 2 \mathrm{H}_{2} \mathrm{O}\right)$. O óxido de silício $\left(\mathrm{SiO}_{2}\right)$ na forma de quartzo presente na massa confere sustentação ao corpo cerâmico, pois não retrai durante a secagem e sinterização o que contribui para a diminuição de trincas. A caulinita é um argilomineral que apresenta pequena expansão, difícil dispersão na água e moderada plasticidade em comparação com os demais argilominerais. Foram identificados também picos característicos da ilita $\left((\mathrm{K}, \mathrm{H}) \mathrm{Al}_{2}(\mathrm{Si}\right.$, $\left.\mathrm{Al}) 4 \mathrm{O}_{10}(\mathrm{OH}) 2 \mathrm{xH}_{2} \mathrm{O}\right)$, corroborando a análise de composição química. A ilita atua como fundente [3].

A composição química o resíduo é constituído basicamente por $\mathrm{SiO}_{2}$ e $\mathrm{Al}_{2} \mathrm{O}_{3}$, que corresponde à cerca de $86 \%$. Os altos teores de sílica e alumina são típicos de rochas metamórficas ornamentais do tipo gnaisse. O resíduo também possui óxidos alcalinos $\left(\mathrm{Na}_{2} \mathrm{O}, \mathrm{K}_{2} \mathrm{O}\right)$, muito importantes nas

Tabela II - Composição química e perda ao fogo da argila e resíduo de rocha ornamental. [Table II - Chemical composition and Loss to the Fire (LF) of clay and dimension stone wastes.]

\begin{tabular}{cccccccccc}
\hline \multicolumn{10}{c}{ Análise Química (\%) } \\
\hline Amostra & $\mathrm{SiO}_{2}$ & $\mathrm{Fe}_{2} \mathrm{O}_{3}$ & $\mathrm{TiO}_{2}$ & $\mathrm{Al}_{2} \mathrm{O}_{3}$ & $\mathrm{~K}_{2} \mathrm{O}$ & $\mathrm{MgO}$ & $\mathrm{CaO}$ & Outros & $\mathrm{PF}$ \\
Argila & 45,60 & 8,67 & 1,31 & 28,40 & 1,22 & 0,81 & 0,32 & 1,07 & 12,60 \\
Resíduo & 71,60 & 3,87 & 0,03 & 14,05 & 4,10 & 1,09 & 1,77 & 2,89 & 0,60 \\
\hline
\end{tabular}




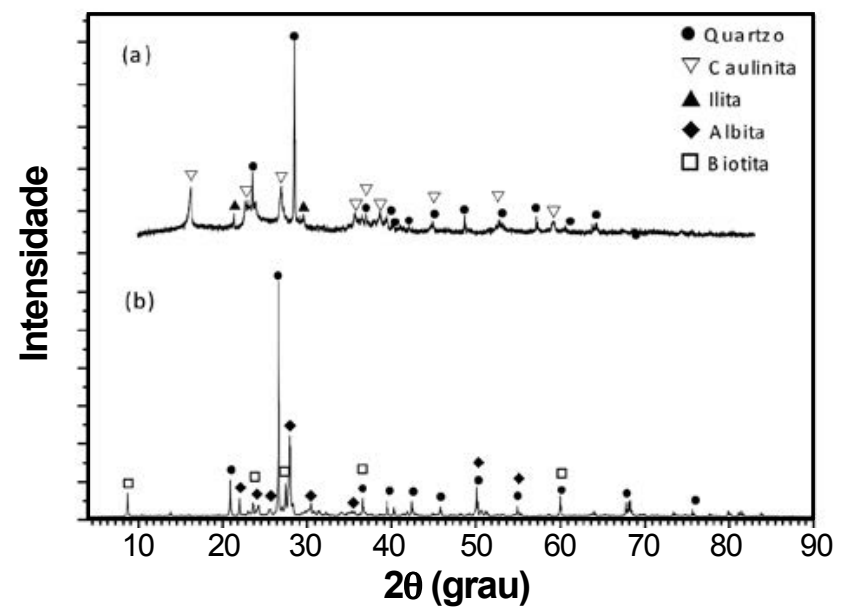

Figura 1: Difratogramas de raios X: (a) argila pura, (b) resíduo de rochas ornamentais.

[Figure 1: X-ray diffraction patterns: (a) pure clay, (b) dimension stones waste.]

formulações cerâmicas, pois atuam como agentes fundentes contribuindo para a sinterização das peças. Foi observada uma pequena quantidade de $\mathrm{Fe}_{2} \mathrm{O}_{3}$, quando comparado com resíduos de rochas ornamentais apresentados na literatura $[2$, $5,6]$. Este constituinte é geralmente relacionado com a adição de granalha como abrasivo no processo de corte/serragem de rochas ornamentais. Porém, neste trabalho o resíduo é oriundo de corte utilizando fio diamantado e, portanto, o óxido de ferro identificado na análise de fluorescência de raios $\mathrm{X}$ é possivelmente de alguma fase cristalina da rocha, por exemplo, Biotita. A alta concentração de ferro na massa cerâmica pode ocasionar a piroplasticidade, caracterizada por uma deformação que ocorre devido à formação de um excesso de fase líquida durante a sinterização do material [10].

A perda ao fogo do resíduo foi de aproximadamente $0,6 \%$ $\mathrm{m} / \mathrm{m}$, valor considerado pequeno para o tipo de resíduo, que originalmente tratava-se de uma lama. Isto ocorreu devido a previa secagem da amostra a $110^{\circ} \mathrm{C}$ até massa constante.

No resíduo, verifica-se que do ponto de vista mineralógico é constituído basicamente de $\mathrm{SiO}_{2}$ (sílica), $\mathrm{Na}\left(\mathrm{AlSi}_{3} \mathrm{O}_{8}\right.$ ) (Albita) e $\mathrm{K}_{2}\left(\mathrm{Fe}_{2.786} \mathrm{Mg}_{2.321} \mathrm{Ti}_{0.550}\right)\left(\mathrm{Al}_{2.413} \mathrm{Si}_{5.587} \mathrm{O}_{20}\right)(\mathrm{OH})_{4}$ (Biotita). Estes resultados confirmam a presença dos constituintes principais de rochas metamórficas, que são ricas em feldspatos e quartzo.

A Fig. 2 mostra os valores de densidade aparente e absorção de água da amostra AR0 sinterizada em diferentes condições de temperatura e tempo. Verifica-se que a densidade aparente das peças aumentou conforme a temperatura de maneira mais significativa do que com o tempo, isso reafirma estudos [13], no qual discute-se que a temperatura é um parâmetro importante na sinterização. O aumento na densificação ocorreu, principalmente acima de $1000{ }^{\circ} \mathrm{C}$, porque parte da massa se transformou em um líquido viscoso e promoveu o rearranjo das partículas, aumentando o tamanho dos grãos e reduzindo a porosidade. Este fenômeno é conhecido como sinterização por fase líquida [14]. Com a redução da porosidade e, conseqüente

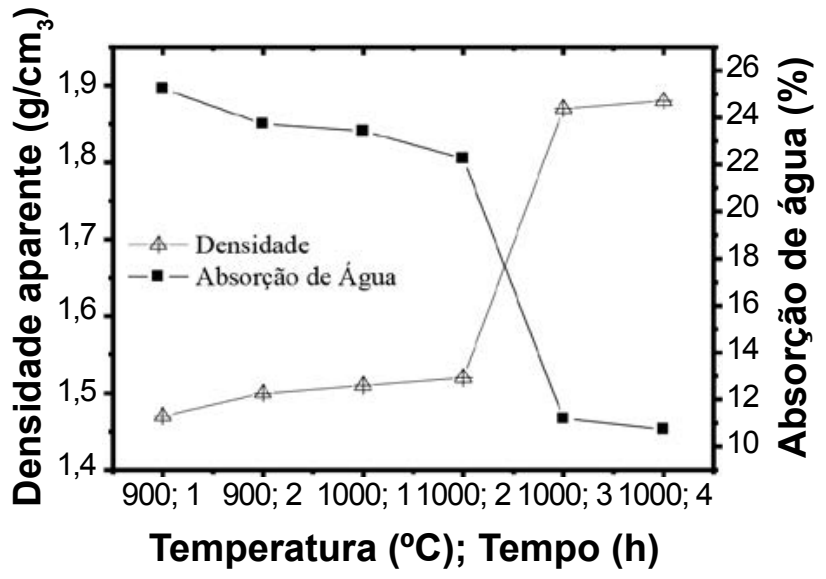

Figura 2: Densidade aparente e absorção de água da amostra AR0 sinterizada a 900,1000 e $1100{ }^{\circ} \mathrm{C}$ por 1 e $2 \mathrm{~h}$.

[Figure 2: Density and water absorption of the ARO sample sintered at 900,1000 and $1100{ }^{\circ} \mathrm{C}$ for 1 to $2 \mathrm{~h}$.]

Tabela III - Módulo de ruptura à flexão e retração linear da amostra AR0 sinterizada a 900,1000 e $1100{ }^{\circ} \mathrm{C}$ por 1 e $2 \mathrm{~h}$. [Table III - Bending strength and linear shrinkage of the ARO sample sintered at 900,1000 and $1100^{\circ} \mathrm{C}$ for 1 and $2 \mathrm{~h}$.]

\begin{tabular}{ccc}
\hline Condição & $\begin{array}{c}\text { Módulo de Ruptura à } \\
\text { Flexão (MPa) }\end{array}$ & $\begin{array}{c}\text { Retração } \\
\text { Linear }(\%)\end{array}$ \\
\hline $900 / 1$ & 5,53 & 2,2 \\
$900 / 2$ & 6,21 & 2,5 \\
$1000 / 1$ & 7,66 & 3,8 \\
$1000 / 2$ & 7,60 & 3,9 \\
$1100 / 1$ & 12,73 & 6,4 \\
$1100 / 2$ & 13,35 & 6,6 \\
\hline
\end{tabular}

aumento da densidade da peça, a absorção de água reduziu.

As amostras sinterizadas a $110^{\circ} \mathrm{C}$ por $2 \mathrm{~h}$ foi à condição que promoveu maior densidade e menor absorção de água das amostras. Entretanto nesta condição, as amostras apresentaram trincas e empenamentos que comprometeram a qualidade final do produto. Neste caso, a condição de tempo e temperatura mais favorável à fabricação de peças foi a de $1100^{\circ} \mathrm{C}$ por $1 \mathrm{~h}$, apresentando valores de densidade aparente e absorção de água iguais a $1,87 \pm 0,04 \mathrm{~g} / \mathrm{cm}^{3} \mathrm{e}$ $11,18 \pm 0,53 \%$, respectivamente.

Observa-se na Tabela III que os valores de módulo de ruptura aumentaram com a temperatura e são diretamente proporcionais à densidade aparente das peças e inversamente à absorção de água. Observa-se também que a retração linear aumentou de maneira mais significativa com a temperatura do que o tempo.

A média dos valores do módulo de ruptura para amostras sinterizadas a $1100{ }^{\circ} \mathrm{C} / 1 \mathrm{~h}$ foi de $11,9 \pm 2,3 \mathrm{MPa}$. O módulo de Weibull foi determinado por meio da linha de tendência da Fig. 3 em comparação com a equação $C$, apresentando um valor de w igual a 5,6. O módulo de Weibull obtido está dentro dos valores que materiais cerâmicos geralmente 
apresentam, entre 3 e 15 [15]. Possivelmente devido à heterogeneidade das amostras ocasionadas na etapa de conformação, acarretando a presença de defeitos superficiais.

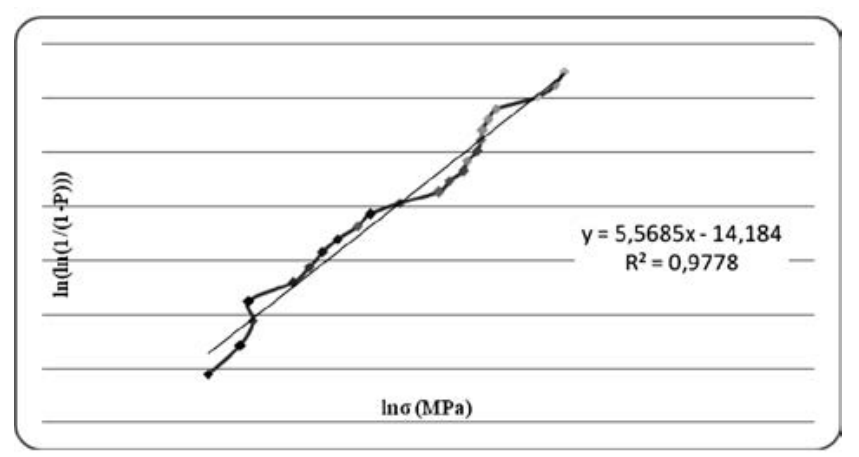

Figura 3: Diagrama de Weibull da cerâmica vermelha sinterizada a $1100{ }^{\circ} \mathrm{C}$ por $1 \mathrm{~h}$

[Figure 3: Weibull diagram of sintered ceramic at $1100{ }^{\circ} \mathrm{C}$ for $\left.1 \mathrm{~h}.\right]$

Na Fig. 4 observa-se que a amostra AR60 obteve valor de absorção de água aproximadamente $9,3 \pm 0,1 \%$ e módulo de ruptura à flexão 15,99 $\pm 0,29 \mathrm{MPa}$. Foram reportados valores de absorção de água entre $9 \%$ e $13 \%$ para composições de 0 a $30 \%$ de resíduos de rochas ornamentais [5], e 11-14 MPa de resistência à flexão [5].

Pela norma ABNT NBR 15270-2 [16], o índice máximo de absorção de água indicado para bloco cerâmico é de $22 \%$, e para telhas do tipo romana segundo a ABNT NBR 13582 [17] é $18 \%$. Com a adição de resíduo de rocha ornamental observase que as cerâmicas apresentaram valores próximos pelo exigido pela norma quando sinterizados até $1000^{\circ} \mathrm{C}$, e valores mais satisfatórios quando sinterizada a $1100{ }^{\circ} \mathrm{C}$ e, portanto, tem potencial para ser aplicado em produtos de cerâmica vermelha. A amostra AR60 indica a composição de uma massa cerâmica com a maior fração de resíduo de rocha ornamental que atende as especificações técnicas para fabricação de telhas e blocos estruturais, por exemplo. A amostra AR80 extrapolou o limite de carga da máquina universal de ensaios mecânicos e, portanto não foi apresentado na Fig. 4 .

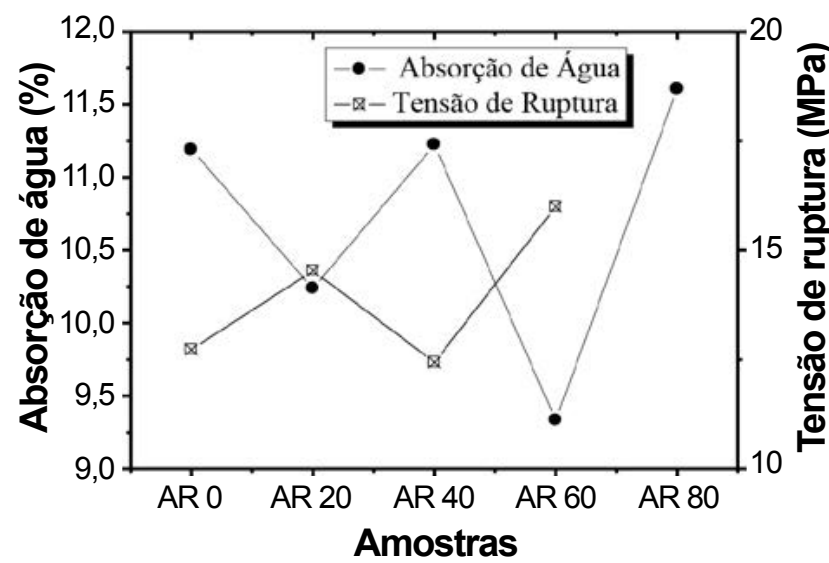

Figura 4: Módulo de ruptura à flexão e absorção de água das amostras.

[Figure 4: Tensile modulus of rupture and water absorption of the samples.]
Na Fig. 5 estão dispostos os valores das retrações lineares das amostras estudadas. As composições apresentam uma leve redução nos valores de retração, aproximadamente $6 \%$. Estes valores foram os mesmos já reportados [5]. É possível dizer que há uma tendência de redução na retração linear à medida que aumenta-se a fração de resíduo. Portanto, a adição de resíduo de rocha ornamental confere maior estabilidade dimensional, o que pode reduzir os defeitos internos e superficiais dos produtos cerâmicos. Este efeito corrobora a análise da composição química quanto ao teor de ferro e sílica. Como exposto, neste trabalho foi utilizado resíduo de rocha ornamental isento de granalha (baixas concentrações de ferro), assim o aumento da fração de resíduo na massa cerâmica implicou na redução do teor de óxido de ferro. A maior estabilidade dimensional pode ser explicada pelo afastamento do efeito da piroplasticidade na cerâmica em conseqüência do baixo teor de ferro do resíduo. Além disso, a alta quantidade de sílica no resíduo minimiza os efeitos da retração.

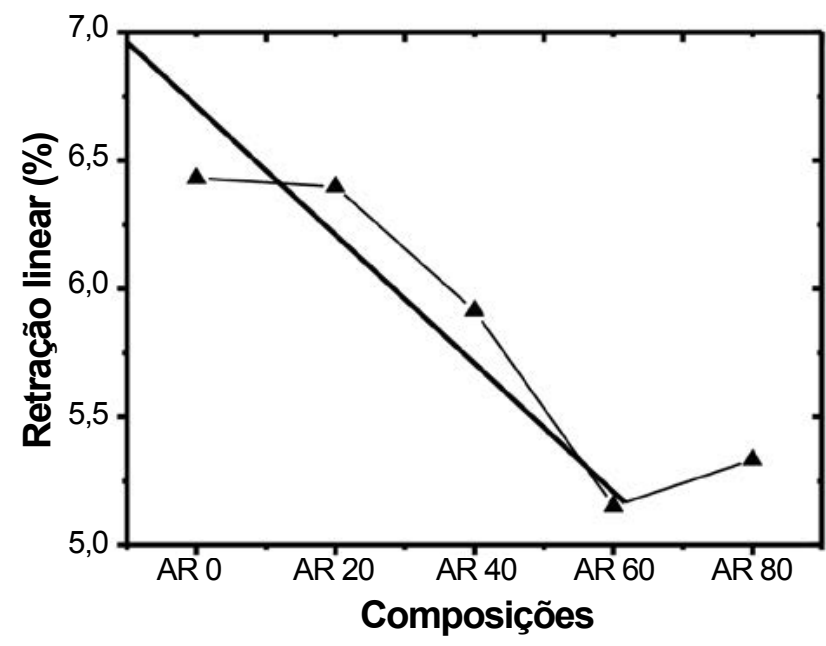

Figura 5: Retração linear das amostras estudadas.

[Figure 5: Linear shrinkage of the samples.]

\section{CONCLUSÕES}

A temperatura é um fator decisivo na densificação de peças de cerâmica vermelha em comparação com o tempo, e influencia diretamente nas propriedades tecnológicas do produto cerâmico. Com o aumento da temperatura, aumentou-se a densidade e tensão de ruptura das peças e reduziu-se a absorção de água. Das condições avaliadas até $1000{ }^{\circ} \mathrm{C}$ as cerâmicas apresentaram propriedades necessárias para aplicação como cerâmica vermelha, e a $1100{ }^{\circ} \mathrm{C}$ por $1 \mathrm{~h}$ tem potencial para ser aplicado como revestimento cerâmico poroso. O módulo de Weibull encontrado foi baixo, porém dentro do intervalo que, geralmente, materiais cerâmicos apresentam, indicando a reprodutividade das amostras e a confiabilidade do ensaio. Observa-se uma redução na retração linear com aumento da fração de resíduo na massa cerâmica. Assim, a adição de resíduo de rocha ornamental sugere maior estabilidade dimensional às placas cerâmicas. 
Tal fenômeno pode ser atribuído aos baixos teores de ferro do resíduo de rocha ornamental utilizado neste trabalho. As amostras AR20, AR40 e AR60 podem ser empregadas na fabricação de telhas e blocos de cerâmica vermelha estrutural, pois possuem propriedades tecnológicas superiores ao indicado pelas normas técnicas dessas classes de produtos. A utilização da composição AR60 é aquela que mais favorece a mitigação de impactos ambientais gerados pelas indústrias de rochas ornamentais, uma vez que possui a maior quantidade de resíduo sem alterar as propriedades tecnológicas significativamente.

\section{AGRADECIMENTOS}

À FAPES/CNPq pelo apoio financeiro.

\section{REFERÊNCIAS}

[1] Abirochas, Balanço das exportações e importações de rochas de janeiro a maio de 2012, disponível em: < http://www.abirochas.com.br/noticias.php>, acesso em 26/06/2012.

[2] J. M. S. Moreira, J. P. V. T. Manhães, J. N. F. Holanda, Reaproveitamento de resíduo de rocha ornamental proveniente do Noroeste Fluminense em cerâmica vermelha, Cerâmica 51, 319 (2005) 180-186.

[3] E. Grun, "Caracterização de Argilas provenientes de Canelinha/SC e estudo de formulações de massas cerâmicas", Diss. Mestrado, Programa de Pós-graduação em Ciência e Engenharia de Materiais, Universidade Estadual de Santa Catarina, Joinvile, SC (2007).

[4] J. C. Santos, T. M. Gomes, S. P. Taguchi, , M. A. Neves, J. P. B. Machado, L. A. Borges Jr, Influência de resíduos de rochas ornamentais na plasticidade de argilas utilizadas em cerâmica vermelha, in $20^{\circ}$ Congresso Brasileiro de Engenharia e Ciência dos Materiais, Joinville, SC (2012).

[5] A. A. Pazeto, M. C. Borlini, A. Caranassios, Caracterização do resíduo proveniente do beneficiamento do granito Iberê Crema Bordeuax e suas aplicações na cerâmica argilosa, XVI Jornada IC, CETEM (2008) 134-140.

[6] J. P. V. T. Manhães, J. M. S. Moreira, J. N. F. Holanda,
Variação microestrutural de cerâmica vermelha incorporada com resíduo de rocha ornamental, Cerâmica 55, 336 (2009) 371-378.

[7] R. R. Menezes, H. S. Ferreira, G. A. Neves, H. C. Ferreira, Uso de rejeitos de granitos como matérias-primas cerâmicas, Cerâmica 48, 306 (2002) 92-101.

[8] Associação Brasileira de Normas Técnicas - ABNT, NBR 7170, "Tijolo maciço cerâmico para alvenaria", Rio de Janeiro, RJ (1983).

[9] Associação Brasileira de Normas Técnicas - ABNT, NBR 15270-2, "Componentes cerâmicos parte 2: Blocos cerâmicos para alvenaria estrutural - Terminologia e requisitos", Rio de Janeiro, RJ (2005).

[10] L. Neckel Jr., Processamento de telhas cerâmicas por compactação de pós e queimas em forno a rolo, Diss. Mestrado, Programa de Pós-graduação em Ciência e Engenharia de Materiais, UFSC, Florianópolis, SC (2008).

[11] Associação Brasileira de Normas Técnicas - ABNT, NBR 15270-3, "Componentes cerâmicos parte 3: Blocos cerâmicos para alvenaria estrutural e de vedação - Métodos de ensaio", Rio de Janeiro, RJ (2005).

[12] Associação Brasileira de Normas Técnicas - ABNT, NBR 8947, "Telha Cerâmica - Determinação da Massa e da Absorção de Água", Rio de Janeiro, RJ (1985).

[13] B. C. A. Pinheiro, J. N. F. Holanda, Efeito da temperatura de queima em algumas propriedades mecânicas de cerâmica vermelha, Cerâmica 56, 339 (2010) 237-243.[14] M. F. Ashby, D. R. H. Jones, "Engenharia de materiais: Uma introdução a propriedades, aplicações e projeto", $3^{a} \mathrm{Ed}$., Vol. 2, Elsevier, Rio de Janeiro, RJ (2007) p.188-191.

[15] E. D. Zanotto, A. R. Migliore Jr., Propriedades Mecânicas de Materiais Cerâmicos: Uma Introdução, Cerâmica 37, 247 (1991) 07-16.

[16] Associação Brasileira de Normas Técnicas - ABNT, NBR 15270-2, "Componentes cerâmicos parte 2: Blocos cerâmicos para alvenaria estrutural - Terminologia e requisitos", Rio de Janeiro, RJ (2005).

[17] Associação Brasileira de Normas Técnicas ABNT, NBR 13582, "Telha cerâmica tipo romana", Rio de Janeiro, RJ (2002).

(Rec.01/05/2013, Rev.04/07/2013, Ac. 08/08/2013) 